\title{
Postmenopausal Bleeding and Changing Bleeding Patterns after Parental Use of Corticosteroids: A Prospective Cohort Study
}

\author{
Henny Anna Rie Klomp¹, Johannes Maria Gulielmus Cobben², Paul Jan Quirien van der Linden ${ }^{*}$ \\ ${ }^{1}$ Department of Obstetrics and Gynecology, Deventer Ziekenhuis, Deventer, The Netherlands \\ ${ }^{2}$ Department of Anesthesiology, Deventer Ziekenhuis, Deventer, The Netherlands \\ Email: *p.j.q.vanderlinden@dz.nl
}

How to cite this paper: Klomp, H.A.R., Cobben, J.M.G. and van der Linden, P.J.Q. (2017) Postmenopausal Bleeding and Changing Bleeding Patterns after Parental Use of Corticosteroids: A Prospective Cohort Study. Open Journal of Obstetrics and Gynecology, 7, 326-333.

https://doi.org/10.4236/ojog.2017.73034

Received: February 13, 2017

Accepted: March 20, 2017

Published: March 23, 2017

Copyright $\odot 2017$ by authors and Scientific Research Publishing Inc. This work is licensed under the Creative Commons Attribution International License (CC BY 4.0).

http://creativecommons.org/licenses/by/4.0/

(c) (i) Open Access

\begin{abstract}
Objective: To study whether there is a relation between the application of corticosteroids and occurrence of postmenopausal bleeding. Also we want to determine whether corticosteroids can cause an irregularity in a previously regular menstruation cycle. Design and Setting. Prospective cohort study in the department of anesthesiology. Patients. 209 women who received a single dosage of corticosteroids as treatment for pain. Interventions. None, observational cohort study; all women received standard care. Main outcome measures: Postmenopausal blood loss or disruption of menstruation cycle. Result. Postmenopausal blood loss or disruption of menstruation cycle were both more common 6 weeks after administration of corticosteroids, but were sometimes also reported 2 weeks after administration of corticosteroids. Conclusion: After administration of corticosteroids in a postmenopausal woman an episode of menstruation like bleeding can be expected. This is probably due to a transient drop of androstenedione. In premenopausal women a transient change in menstruation cycle can be observed.
\end{abstract}

\section{Keywords}

Postmenopausal Bleeding, Corticosteroids, Bleeding Patterns

\section{Introduction}

Postmenopausal blood loss is a very common problem in women. It can have multiple causes and endometrial carcinoma is the most serious [1]. In a large Scandinavian study a variation of age specific incidence of postmenopausal blood loss was shown. It ranges from 14.6 per 1000 (CI 10.1 - 20.3) in women younger than 50 years of age to 1.7 per 1000 (CI $1.1-2.6$ ) in women over 80 
years. On the other hand, the risk that this blood loss is caused by endometrial carcinoma is less than $1 \%$ in women under 50 years of age, but increases to $24 \%$ in women over the age of 80 [2].

In a previous study, we showed that postmenopausal blood loss can occur after prior administration of corticosteroids, in particular when they are parentally administered [3]. It was also shown that corticosteroids can influence the menstrual cycle [4]. Because this medication is widely used by various doctors for all kinds of painful or inflammatory conditions such as in orthopedic surgery, ophthalmology and anesthesiology we want to investigate this possible connection as a cause of a common gynecological complaint.

The primary aim of this study is to determine whether there is a relation between the application of corticosteroids and occurrence of postmenopausal bleeding. Also we want to determine whether corticosteroids can cause an irregularity in a previously regular menstruation cycle. To this end we performed a prospective cohort study in women who received a single dosage of corticosteroids in the department of anesthesiology as treatment for pain.

\section{Material and Method}

We performed a prospective cohort study. All female patients visiting the department of anesthesiology, who met the inclusion criteria, were invited to participate in this study prior to their corticosteroids injection. They gave written informed consent for two questionnaires via email and permission to check their medical record if necessary.

Hereafter, we made two groups based on their pre- and postmenopausal status. The first questionnaire was sent two weeks after application of corticosteroids. We collected baseline characteristics (for instance age, weight, smoking, co-morbidity) and data on vaginal blood loss. The second questionnaire was sent six weeks after application of corticosteroids. With that questionnaire we collected data regarding blood loss and changes in medication. From postmenopausal women who reported vaginal blood loss we checked their medical record on endometrial sampling and reports of histopathology.

Inclusion criteria were: premenopausal women with regular menstrual cycles, defined as cycles between 25 - 35 days during at least 6 previous months. Postmenopausal women were defined as at least one year of no menstrual bleeding before intervention with corticosteroids. Exclusion criteria were age under 18 years, not having access to a computer, irregular menstrual cycles, use of hormonal therapy (oral contraceptive pill or HRT), known bleeding disorders, a history of hysterectomy or endometrial ablation, or known endocrinologic diseases (i.e. thyroid problem).

For statistical analysis we used student t-test, Mann-Whitney $\mathrm{U}$ test, Kruskall Wallis test and Wilcoxon signed rank test, when appropriate. We also performed a univariate and multivariate logistic regression analysis.

All women received standard care, i.e. they were referred to the gynecologist or general practitioner when either irregular menstrual of cycle postmenopausal 
bleeding appeared. Therefore the approval of our Institutional Review Board was given. Since a non-interventional prospective observational study, i.e. a non WMO-study, was performed.

\section{Results}

Between November 2013 and December 2014, 209 women were selected and gave their written informed consent. They were initially referred to the anesthesiology department for corticosteroid injection for treatment of joint and musculoskeletal pain problems. They all were treated with $40 \mathrm{mg}$ or $80 \mathrm{mg}$ Kenacort $^{\circ}$ (Triamcinolon). They all received an invitation via e-mail to complete a questionnaire and if necessary up to 2 reminders; 152 (72.7\%) women completed the first questionnaire, 145 (69.3\%) women completed both questionnaires.

The demographical features are presented in Table 1 . There were no significant differences between both groups, except for mean age (pre-menopausal 40 years and post-menopausal 61 years).

Table 1. Demographical features in participants.

\begin{tabular}{|c|c|c|c|}
\hline & \multicolumn{2}{|c|}{ Two weeks post corticosteroids $(\mathrm{n}=152)$} & \multirow{2}{*}{ p-value } \\
\hline & Premenopausal $(\mathrm{n}=64)$ & Postmenopausal $(\mathrm{n}=88)$ & \\
\hline Age shown mean $(\mathrm{sd}) \circ$ & $40.3(7.5)$ & $61.6(8.4)$ & 0.000 \\
\hline Smoking* $^{*}$ & 22 & 19 & 0.081 \\
\hline Multiparous ${ }^{*}$ & 52 & 68 & 0.463 \\
\hline Medication* $^{*}$ & 48 & 57 & 0.061 \\
\hline \multicolumn{4}{|l|}{$\mathrm{BMI} \dagger$} \\
\hline $18-25 \mathrm{~kg} / \mathrm{m}^{2}$ & 27 & 44 & \multirow{4}{*}{0.142} \\
\hline $25-30 \mathrm{~kg} / \mathrm{m}^{2}$ & 19 & 30 & \\
\hline $35-40 \mathrm{~kg} / \mathrm{m}^{2}$ & 15 & 13 & \\
\hline \multirow[t]{3}{*}{$>40 \mathrm{~kg} / \mathrm{m}^{2}$} & 2 & 0 & \\
\hline & \multicolumn{2}{|c|}{ Six weeks post corticosteroids $(\mathrm{n}=145)$} & \multirow{2}{*}{ p-value } \\
\hline & Premenopausal $(n=62)$ & Postmenopausal $(\mathrm{n}=83)$ & \\
\hline Age shown mean $(\mathrm{sd}) \circ$ & $40.5(6.9)$ & $61.5(8.5)$ & 0.000 \\
\hline Smoking* & 22 & 18 & 0.067 \\
\hline Multiparous $^{*}$ & 50 & 64 & 0.521 \\
\hline Medication $^{*}$ & 47 & 54 & 0.094 \\
\hline Change in medication* & 13 & 16 & 0.802 \\
\hline \multicolumn{4}{|l|}{$\mathrm{BMI} \dagger$} \\
\hline $18-25 \mathrm{~kg} / \mathrm{m}^{2}$ & 26 & 42 & \\
\hline $25-30 \mathrm{~kg} / \mathrm{m}^{2}$ & 18 & 28 & 0.115 \\
\hline $35-40 \mathrm{~kg} / \mathrm{m}^{2}$ & 15 & 12 & \\
\hline$>40 \mathrm{~kg} / \mathrm{m}^{2}$ & 2 & 0 & \\
\hline
\end{tabular}

$\mathrm{sd}=$ standard deviation. $\circ=$ Student $\mathrm{t}$-test ${ }^{*}=$ Mann-Whitney $\mathrm{U} ; \dagger=$ Kruskall-Wallis. 
In Table 2 we present changes in bleeding pattern or presence of postmenopausal blood loss. Both events were more common 6 weeks after administration of corticosteroids, but were sometimes also reported 2 weeks after administration of corticosteroids.

In premenopausal women group $(\mathrm{n}=62)$, bleeding pattern was changed in 22 women (35.5\%) after 2 weeks and in 37 women $(59.7 \%)$ after 6 weeks $(\mathrm{p}<0.05)$.

In postmenopausal women $(\mathrm{n}=83)$ vaginal blood loss was reported in 6 (7.2\%) women after 2 weeks and in $9(10.8 \%)$ women after 6 weeks $(p=0.31)$. However, when we performed regression analysis we did not find any significant differences in individual variables (smoking, BMI and parity).

The histopathological data of women with postmenopausal blood loss, within 6 week follow-up, were collected from their medical records and are shown in Table 3. In only one case an endometrial sample was reported. It did not show histopathological changes of endometrial tissue. In the other twelve women that had postmenopausal blood loss, no endometrial samples were taken. Mostly, because no abnormal endometrial thickness was noted and hence endometrial sampling was not found obligatory.

\section{Discussion}

Corticosteroids have an influence on both pre- and postmenopausal women with respect to vaginal blood loss. In premenopausal women we noted an increase of disturbance of the menstruation cycle. In post-menopausal women presence of postmenopausal vaginal blood loss was noted. This increase of incidence was more prominent in premenopausal women.

In the group of premenopausal women we found a significant difference in the presence of bleeding irregularities, when we compared the number of events

Table 2. Bleeding differences in time ( $\mathrm{n}=145$, information from both questionnaires).

\begin{tabular}{cccc}
\hline & $\begin{array}{c}\text { Two weeks post } \\
\text { corticosteroids }\end{array}$ & $\begin{array}{c}\text { Six weeks post } \\
\text { corticosteroids }\end{array}$ & p-value \\
\hline Premenopausal $(\mathrm{n}=62) \ddagger$ & $22(35.5 \%)$ & $37(59.7 \%)$ & 0.019 \\
Missing data & 7 & 0 & 0.317 \\
Postmenopausal $(\mathrm{n}=83) \ddagger$ & $6(7.2 \%)$ & $9(10.8 \%)$ & - \\
\hline
\end{tabular}

$\ddagger=$ Wilcoxon signed rank.

Table 3. Follow-up in women with postmenopausal blood loss after corticosteroids $(\mathrm{n}=$ 83).

\begin{tabular}{lccc}
\hline & Percentage & No follow up & Pathohystological report \\
\hline Only after 2 weeks $(\mathrm{n}=4)$ & $4.8 \%$ & $\mathrm{n}=3$ & No report of histopathology* \\
After 2 \& 6 weeks $(\mathrm{n}=3)$ & $3.6 \%$ & $\mathrm{n}=2$ & No histopathological changes \\
Only after 6 weeks $(\mathrm{n}=6)$ & $7.2 \%$ & $\mathrm{n}=5$ & No report of histopathology \\
\hline
\end{tabular}

- = endometrium $<4 \mathrm{~mm}$. 
after respectively two and six weeks post corticosteroids administration. Six weeks after administration $59.7 \%$ of premenopausal participants experienced a change in their menstrual cycle, whereas after two weeks only $35.5 \%$ had reported changes in their menstrual cycle. Glucocorticosteroids affect a menstrual cycle due to their effect on two organs. Both the pituitary gland and the ovary, producing estrogens and progesterone are directly inhibited [5]. This causes a temporary change in menstrual cycle, and after prolonged use of medication these effects might be more prominent.

In our previous study we hypothesized a pathophysiological pathway that might cause postmenopausal bleeding. Since there is a positive correlation between the conversion of androgens to estrogen and bodyweight, we hypothesized that there would be more endogenous estrogen in over weighted postmenopausal women. Therefore, they might have more endometrial proliferation. If a transient lower level of circulating estrogens occurs, caused by a drop of androstenedione after adrenal suppression by corticosteroids, a menstruation like withdrawal of endometrium will follow. This transient change in circulating hormones might explain the elapsed time between corticosteroid use and vaginal bleeding [6].

In our previous study no histopathological changes in endometrial tissue were found, hence we expected a similar finding in this cohort [3]. Surprisingly, in only one woman out of 14 we found a report on histopathology (no pathological changes in endometrial tissue). In the other 13 women collection of an endometrial sample was not found necessary by their caretakers. The majority of these women were not referred to have an endometrial sample or hysteroscopy. This leaves us with the question on the findings on further histopathology due to the nature of our study that is based mainly on questionnaires.

In contrast to our hypothesis, our present study did not show a direct significant influence of weight or BMI on our results. Although our sample size was rather big, only a limited number of events did occur. From 145 women who answered both questionnaires, only thirteen reported postmenopausal blood loss. This is what we expected taking into account the population based risk as noted above [2]. Despite the fact there might be a possible lower detection rate because we could only rely on patient response in questionnaires. Although, we could not significantly prove weight or for that matter BMI as independent risk factors for postmenopausal blood loss after corticosteroids, overweight still remains a known risk factor for postmenopausal blood loss per se [6]. Therefore, the amount of peripheral fat and bodyweight might be of influence. If this would be tested, one should perform a study, selecting only postmenopausal women who meet in- and exclusion criteria and have postmenopausal blood loss after corticosteroid injection. We performed a power calculation to predict a sample size for such a study. It showed a necessary number of at least 14 overweight women with postmenopausal blood loss only due to corticosteroid injection to find a correlation coefficient of 0.7. Over all, we are convinced that all women with abnormal blood loss should be seen by a gynecologist to rule out pathology. 
We performed a prospective cohort study on the effects of corticosteroids in pre- and postmenopausal women, with a six-week follow-up. To our knowledge, this is the first prospective study published. Only one retrospective study is published before regarding this subject [7]. Possible corticosteroid effects are mentioned a few times in recent literature by others in case series [7] [8] [9] [10] [11]. Most authors report case series with a similar problem as mentioned by us in our previous study [3]. All authors reported a comparable clinical pathway, namely corticosteroids give a transient increase of disrupted menstrual period or might cause postmenopausal vaginal blood loss. However, none of them performed a prospective study in which all patients were treated in the same anesthesiology department and got two questionnaires afterwards.

Since postmenopausal blood loss and disrupted menstruation cycle are very common complaints in gynecological day to day practice, to study a possible cause is important. Our present study shows an increase in abnormal vaginal blood loss, both in pre- and postmenopausal women. We believe this is caused by a pathway as explained above. However, a limitation of this study is we were not able to ascertain our hypothesis. It would be necessary to take multiple serial blood samples to mark the moment of androstenedione drop and subsequent withdrawal bleeding. Ideally, blood samples should be taken in ovarian veins, since this would give an optimal representation of hormonal levels surrounding the ovaries [12]. Since serial ovarian vein blood samples are no option due to the nature of the sampling method, we do not expect it possible to realize. On the other hand, we found very few endometrial samples with respect to the number of women with postmenopausal blood loss. If we take daily practice in account we can explain this rather surprising feature. We wanted to see how it was done in daily practice in a furthermore healthy group of patients that got corticosteroid treatment for other conditions, namely pain relief, while not having gynecological complaints before. If they were experiencing blood loss, they would probably seek help from their general practioner and some of them became referred to us, thereafter. A second limitation in our study design is we did not take routinely endometrial samples from all women with postmenopausal bleeding. This is only indicated when there is an ultrasound measurement of endometrial thickness above $4 \mathrm{~mm}$ [13]. Because we performed a prospective cohort study on the presence of changes in menstruation or the presence of postmenopausal blood loss, routine endometrial sampling was no part of this study.

Since corticosteroids are very commonly applied in everyday practice, it is mandatory to know incidences of side effects. Our study shows a significant transient influence on a previous regular menstrual cycle. Our findings can be of help in counseling women who will be treated with corticosteroids, in warning them for possible changes in their menstruation cycle that can occur. Based on our findings, we suggest that patients should be additionally counseled on changes in menstrual cycle or occurrence of postmenopausal blood loss when they are going to get treatment involving parenteral corticosteroids. However, 
we also still recommend these women to seek help from their general practitioner or gynecologist when an abnormal bleeding pattern has occurred. It remains of pivotal importance to rule out other etiologies of abnormal vaginal bleeding, regardless the woman's age.

\section{Conclusions}

After administration of corticosteroids in a postmenopausal woman an episode of menstruation like bleeding can be expected. This is probably due to a transient drop of androstenedione. In premenopausal women a transient change in menstruation cycle can be observed.

However, since postmenopausal blood loss is also an early sign of gynecologic malignancy, we believe all women with this complaint should be referred to or visit a gynecologist.

\section{Acknowledgements}

We thank all women who participated in our study and especially our nurses and office managers of the anesthesiology department.

\section{References}

[1] Emanuel, M.H., Verdel, M.J., Wamsteker, K. and Lammes, F.B. (1995) A Prospective Comparison of Transvaginal Ultrasonography and Diagnostic Hysteroscopy in the Evaluation of Patients with Abnormal Uterine Bleeding: Clinical Implications. American Journal of Obstetrics \& Gynecology, 172, 547-552. https://doi.org/10.1016/0002-9378(95)90571-5

[2] Gredmark, T., Kvint, S., Havel, G. and Mattsson, L.A. (1995) Histopathological Findings in Women with Postmenopausal Bleeding. British Journal of Obstetrics and Gynaecology, 102, 133-136. https://doi.org/10.1111/j.1471-0528.1995.tb09066.x

[3] Klomp, H.A. and van der Linden, P.J. (2013) Postmenopausal Bleeding and Corticosteroids. Gynecologic and Obstetric Investigation, 76, 260. https://doi.org/10.1159/000351105

[4] Mens, J.M., Nico de Wolf, A., Berkhout, B.J. and Stam, H.J. (1998) Disturbance of the Menstrual Pattern after Local Injection with Triamcinolone Acetonide. Annals of the Rheumatic Diseases, 57, 700. https://doi.org/10.1136/ard.57.11.700

[5] Petraglia, F., Musacchio, C., Luisi, S. and De Leo, V. (2008) Hormone-Dependent Gynaecological Disorders: A Pathophysiological Perspective for Appropriate Treatment. Best Practice \& Research Clinical Obstetrics \& Gynaecology, 22, 235-249. https://doi.org/10.1016/j.bpobgyn.2007.07.005

[6] Speroff, L., Glass, R.H. and Kase, N.G. (1999) Clinical Gynecologic Endocrinology and Infertility. 6th Edition, Lippincott Williams \& Wilkins, Philadelphia.

[7] Suh-Burgmann, E., Hung, Y.Y. and Mura, J. (2013) Abnormal Vaginal Bleeding after Epidural Steroid Injection: A Paired Observation Cohort Study. American Journal of Obstetrics \& Gynecology, 209, 206.e1-206.e6. https://doi.org/10.1016/j.ajog.2013.06.045

[8] Gowri, V. (2013) An Unusual Cause of Postmenopausal Bleeding. British Medical Journal Case Reports 2013.

[9] Hirsch, J.G. and Hsu, E.S. (2012) Abnormal Uterine Bleeding Following Lumbar 
Epidural Corticosteroid Injections and Facet Medial Branch Blocks in Both Pre- and Postmenopausal Women: A Case Series. Pain Medicine, 13, 1137-1140.

https://doi.org/10.1111/j.1526-4637.2012.01445.X

[10] James, L.M. and Carneiro, K. (2014) Abnormal Uterine Bleeding in a Postmenopausal Woman after an Intra-Articular Knee Injection with Triamcinolone: A Case Report. Physical Medicine and Rehabilitation, 6, 656-658. https://doi.org/10.1016/j.pmrj.2013.11.015

[11] Kerner, J.A. (1986) Postmenopausal Bleeding Associated with Corticosteroid Administration. Journal of the American Medical Association, 255, 2897-2898. https://doi.org/10.1001/jama.1986.03370210065017

[12] Heineman, M.J., Sluijmer, A.V. and Evers, J.L. (1993) Utero-Ovarian Vein Blood Sampling in Postmenopausal Women. Fertility and Sterility, 60, 184-186.

[13] Dijkhuizen, F.P., Brolmann, H.A., Potters, A.E., Bongers, M.Y. and Heinz, A.P. (1996) The Accuracy of Transvaginal Ultrasonography in the Diagnosis of Endometrial Abnormalities. Obstetrics \& Gynecology, 87, 345-349.

Submit or recommend next manuscript to SCIRP and we will provide best service for you:

Accepting pre-submission inquiries through Email, Facebook, LinkedIn, Twitter, etc. A wide selection of journals (inclusive of 9 subjects, more than 200 journals)

Providing 24-hour high-quality service

User-friendly online submission system

Fair and swift peer-review system

Efficient typesetting and proofreading procedure

Display of the result of downloads and visits, as well as the number of cited articles

Maximum dissemination of your research work

Submit your manuscript at: http://papersubmission.scirp.org/

Or contact ojog@scirp.org 